\title{
En busca de la alteridad
}

\section{Chasing the otherness}

César Augusto Muñoz Marín Comunicador social por la Universidad Santo Tomás. Asistente de investigación. Candidato a magister en Antropología por la Universidad de los Andes. Asesor de la Comisión de Búsqueda de Personas Desaparecidas. Responsable del área de comunicaciones de la Asociación de Familiares de Detenidos Desaparecidos cesaragusmunoz@gmail.com

Artículo de reflexión

Fecha de recepción: 2 de noviembre de 2013 • Fecha de aprobación: 30 de noviembre de 2013

\section{Resumen}

Con base en el trabajo etnográfico que supone de acompañamiento de familiares de personas desaparecidas, el artículo analiza cómo, históricamente, la racionalización de la muerte, un fenómeno típicamente occidental, ha devenido en procesos de exclusión y de doble negación del otro: de su vida y de su muerte. El ensayo finaliza con algunas consideraciones deliberadamente inconclusas sobre las representaciones mediáticas sobre la muerte y la desaparición forzada.

Palabras clave: desaparición forzada, exclusión de la alteridad, medios de comunicación.

\section{Abstract}

Based on ethnographic work involved accompanying relatives of missing persons, the article analyzes how, historically, the rationalization of death, a typically Western phenomenon, has become in the process of exclusion and double negation of the other: both its own life and his 
death. The essay ends with some deliberately unfinished thoughts about media representations of death and disappearance.

Keywords: Forced disappearance, exclusion of otherness, media.

\section{INTRODUCCIÓN}

A él y a todos los que un día se llevaron.

«Escribo una carta: porque falta —o porque quiero que faltela presencia, la inminencia. La mía y la del destinatario. La escritura se convierte en "Presente en cuanto guarda inmóvil de la ausencia".

Escribo un libro: es testimonio de la ausencia de los lectores (desconocidos, distantes), testimonio de mi ausencia presente y futura, de mi ausencia inminente: es el testimonio-testamento de alguien que ya no está: de nuevo la presencia de una ausencia».

Patxi Lanceros (2000)

En el proceso de acompañamiento a los familiares víctimas de desaparición forzada, especialmente en la Asociación de Familiares de Detenidos Desaparecidos (Asfaddes), he participado en la elaboracion de artículos, cartillas, documentales, vídeos, crónicas y otras tantas formas de narrar que me han conminado a preguntarme cómo escribir sobre la ausencia, la muerte y el dolor, cómo encontrar las palabras precisas para describir esos rostros cuarteados de arrugas de tanto esperar y buscar. Este ensayo hace parte de una serie de intentos (Muñoz, 2013) por recoger algunas "palabras nómadas», que surgen de encuentros cotidianos en la labor de acompañar a los familiares víctimas de desaparición forzada. Estos encuentros, que van desde los recorridos propios de la acción política, hasta las más elementales actividades de oficio en las labores de la función pública, corresponden claramente con lo que la etnografía caracteriza como la «observación participante», que 
aglutina una variedad amplia de metodologías que van desde los itinerarios o historias de vida individual y colectivas hasta la conversación informal. El investigador no solo observa los procesos sociales que le interesen, sino que adicionalmente participa, en la medida de lo posible, en su vida social (Centro de Memoria Histórica, 2012, p. 41).

Desde los lager ${ }^{1}$ de la segunda guerra mundial, en Europa, hasta las tecnologías de tortura inventadas por los grupos paramilitares en Colombia, la desaparición forzada ha sido el procedimiento más eficaz para excluir todo sentido de alteridad, es la sofisticación de la exclusión del otro.

Ante este proyecto trasnacional de olvido generalizado, la acción del sobreviviente que representa la ausencia (Mélich, 2001) se ha convertido en el mecanismo para reconstruir los hechos truncados por la evaporación del otro. Estas formas propias de contar desde el dolor han generado todo un movimiento alrededor del mundo que ha ido conquistando avances en materia jurídica, ante los reclamos de familiares por saber la verdad y acceder a la justicia. Estos avances han ido acompañados de sendas industrias editoriales y académicas que, aún con sus vacíos, han centrado sus estudios en el campo jurídico y psicológico.

Para el caso colombiano, desde el punto de vista académico, es claro el déficit de lecturas de orden sociológico y antropológico alrededor de las dimensiones del crimen y sus causas más elementales, como si predominara una especie de miedo generalizado cuando se pretende hablar de los elementos estructurales de la exclusión. En el sector académico e intelectual, reina una especie de comodidad, producto de un «efecto Colciencias» por el cual, al decir del profesor Alejandro Castillejo, «las ideas fueron reemplazadas por formalismos universitarios» (Castillejo, 2013, p. 28).

1 En alusión a los campos de concentración nazis, lager se define como el espacio sin tiempo, “el espacio total”. En efecto, el prisionero desde el momento en que es internado en el campo es despojado de su tiempo, de su pasado, de su nombre, de sus pertenencias y de su futuro, ya que del campo sólo se sale por la chimenea, y las tumbas serán "tumbas en el aire”, [al decir de] Paul Celan». (Mélich, 2001, p. 23). Acotación entre corchetes inserta aquí, fuera del original. 
Este documento pretende relacionar la desaparición forzada con la forma como se ha construido desde la exclusión la idea de la muerte en Occidente. En ese sentido, el ensayo está organizado en tres partes. La primera, de orden histórico, La muerte como exclusión del otro: una construcción de Occidente", es una mirada alrededor de las prácticas en torno a la muerte en el mundo occidental, el papel que han jugado instituciones como la Iglesia, la construcción social de lo que conocemos hoy como cementerio; un espacio regido por una organización socio-territorial de orden vertical en donde predominan relaciones de tipo económico propias de la actividad capitalista.

La segunda parte, titulada No nombre, no lugar, es la sistematización de un proceso de acompañamiento a la labor de diagnóstico que realiza el Instituto Nacional de Medicina Legal y Ciencias Forenses en algunos cementerios del país. La visita a estos cementerios la realicé como parte del equipo asesor de la Comisión de Búsqueda de Personas Desaparecidas, $\mathrm{CBPD}^{2}$.

Esta parte del ensayo se construye sobre la idea elemental de la doble desaparición: la desaparición física del cuerpo en el momento que la persona es sustraída de su espacio vital, y luego el recorrido de la exclusión, como he dado en llamar al proceso administrativo que condena a un cuerpo a habitar en el mejor de los casos en una bóveda anclada en el último rincón del cementerio demarcada con la sigla NN. Lamentablemente, en las situaciones más comunes estos cuerpos habitan la «promiscuidad de la fosa común» (Castillejo, 2013, p. 25).

2 Es importante reconocer la labor que las nueve instituciones y organizaciones que conforman la Comisión de Búsqueda de Personas Desaparecidas, CBPD, han venido realizando en torno al tema de la desaparición forzada en general y, en particular, en relación con la situación de los cementerios en el país, con diagnósticos y reconocimientos detallados de la problemática. La CBPD es un organismo permanente creado por la Ley 589 de 2000, encargado de apoyar y promover la investigación del delito de desaparición forzada, acatando las competencias de las instituciones que la conforman y las facultades de los sujetos procesales. De antemano agradezco a este organismo y a cada una de las instituciones y organizaciones que lo conforman especialmente al Instituto Nacional de Medicina Legal por permitirme acompańar el proceso de diagnóstico que viene adelantando en los cementerios del país. 
De acuerdo con la idea de indagar desde la investigación participante, en este artículo recogeré algunas historias con base en notas que fui escribiendo durante las visitas a los cementerios.

La última parte, Enarbolando dignidad, pretende hacer algunos comentarios sobre la relación entre desaparición forzada, información e indiferencia, un tema que indago desde mi postura como comunicador y en el cual, a modo de puntos suspensivos, pretendo dejar algunos cuestionamientos sobre el sinsentido de estos mecanismos de violencia estructural.

\title{
LA MUERTE COMO EXCLUSIÓN DEL OTRO: UNA CONSTRUCCIÓN DE OCCIDENTE
}

\begin{abstract}
$\mathrm{Al}$ principio, este ensayo se había pensado a modo de informe periodístico que testimoniara la situación de las personas desaparecidas en algunos cementerios del país, con el fin de sistematizar las labores que desde hace más de cuatro años viene realizando la CBPD acerca de este tema. Las preguntas axiales aquí serían entonces: ¿qué sentido tiene hacer una lectura histórica del tema? ¿Por qué retroceder la mirada tantos siglos atrás si en últimas lo que se pretende abordar un tema de actualidad?
\end{abstract}

En noviembre de 2012, se realizó en Barrancabermeja el segundo espacio de diálogo sobre desaparición forzada del Magdalena medio. El Fondo de Justicia Transicional del Programa de Naciones Unidas para el Desarrollo, PNUD, facilitó la interlocución entre los delegados de la Comisión de Búsqueda y las organizaciones del Magdalena medio $^{3}$. En este encuentro, las organizaciones sociales presentaron un documento

3 Este encuentro se realizó dada la grave situación de desapariciones forzadas en la región. Barrancabermeja es la capital petrolera del país y la ciudad principal de la zona del Magdalena medio, durante las décadas de los setenta y ochenta fue una región reconocida por los fuertes procesos de movilización social principalmente agenciados por la Unión Sindical Obrera USO. Desde finales de los años ochenta, este municipio ha sufrido un proceso de violencia sistemática que deja a su paso miles de personas desaparecidas, asesinadas y desplazadas. Para profundizar en el contexto se pueden consultar los documentos del Programa de Desarrollo y Paz del Magdalena Medio. En ese contexto de violencia, desde el año 2011 se han incrementado las desapariciones forzadas en la región, especialmente de mototaxistas, fenómeno que las organizaciones locales y autoridades han llamado el 
de 23 propuestas locales para salirle al paso a la grave situación de desapariciones forzadas que en los últimos dos años se ha incrementado en la región; a su vez, los integrantes de la CBPD expusieron los avances en la materia de cada una de sus instituciones miembros.

Al finalizar este encuentro, con un equipo del Instituto de Medicina Legal y un funcionario del programa de derechos humanos de la Presidencia de la República, nos dirigimos hacía el Cementerio Central de esta ciudad ${ }^{4}$. Los múltiples matices de verdes y azules contrastan con los tonos grises de las tumbas apiñadas unas tras otras, sin casi el más mínimo espacio intermedio: una verdadera sobrepoblación de la muerte. Desde el silencio de los sepulcros, este lugar grita la historia de violencia que ha sufrido el territorio. Esta necrópolis nos interpela sobre las tecnologías y maquinarias de la muerte que se han puesto en marcha en el país. Son allí notorias las contradicciones: un paisaje colorido como telón de fondo de un horizonte de tumbas y cruces de madera, y, atrás, una construcción al estilo capilla moderna. Las imágenes guardan el hedor y la podredumbre propia de los muertos que se descomponen a la espera de un lugar donde poder ser enterrados.

Al salir de allí, las sensaciones de impotencia, tristeza y rabia se fueron mezclando con el sinsabor del vómito y las náuseas, desde ese instante no dejo de preguntarme en qué momento la muerte se convirtió en un asunto de transacción, en el que, por delegación, otros pagan por un espacio en el que el muerto pueda ser ubicado. Por supuesto, de esa transacción quedan excluidas las personas a las que la violencia les arrebató hasta la identidad.

"caso Tenerife", porque, en su mayoría, las personas desaparecidas y torturadas son encontradas en el municipio de Tenerife. Durante la escritura de este ensayo, la revista Semana publicó el artículo el "Dexter criollo" (se puede ver en http://www.semana.com/nacion/articulo/luis-ramirez-dexter-criollo/330723-3), en referencia a la captura de Luis Gregorio Ramírez por ser el supuesto responsable de más de las treinta desapariciones de personas sucedidas desde el ańo 2011. La revista desconoce completamente la labor de las organizaciones y de algunas instituciones que han hecho seguimiento detallado al caso, en cambio da por hecho que el caso corresponde a un asesino serial.

4 Para hacer seguimiento a la situación del cementerio local de Barrancabermeja se puede ver la nota publicada en el año 2010 por el periódico Vanguardia: ver en http://www.vanguardia.com/historico/72355 -sigue-el-abandono-en-el-cementerio-central. 
La ansiedad por encontrar alguna respuesta a estas preguntas profundamente existenciales me llevó a voltear la hoja y a buscar en el pasado respuestas, ese es el verdadero sentido del siguiente contexto histórico.

\title{
LA MUERTE DE LA ALTERIDAD
}

\author{
"Es en parte la muerte del otro \\ la que nos hace vivir la amenaza de afuera hacia dentro; \\ merced al horror del silencio de los ausentes que no responden más, \\ la muerte del otro penetra en mi como una lesión de nuestro ser común. \\ La muerte me "toca" en la medida en que yo también soy otro para los otros y \\ finalmente para mi mismo, extraño a las palabras de todos los hombres».
}

Paul Ricceur (1954, p. 36)

La experiencia de la muerte es ante todo un proceso de alteridad, es la certeza más clara de la presencia de los otros en nuestras vidas. El asunto se torna complejo y existencial, en la medida en que la presencia es a la vez ausencia: «la desaparición del otro amado produce ante todo una impresión de vacío y al mismo tiempo de presencia/ausencia... es la existencia de alguien o algo en otro lado» (Thomas, 1983, p. 279).

Este proceso de dar sentido al otro ausente se ha visto frustrado en Occidente debido a las prácticas de exclusión en torno a la muerte: «la muerte del otro sólo alcanza verdadera magnitud si yo estoy presente y soy auténtico participante. Pero con demasiada frecuencia al menos en Occidente el hombre muere solo o solamente con extraños insensibles a quienes no les concierne esa muerte» (Thomas, 1983).

Louis Vincent Thomas analiza las prácticas en torno a la muerte en Occidente en comparación con los rituales de poblaciones del África negra, donde «el hombre jamás muere solo, salvo, precisamente en los casos de mala muerte» (Thomas, 1983, p. 291). 
Una de las tantas razones por las cuales las prácticas y rituales en torno de la muerte en Occidente se basan en la exclusión del otro, tiene que ver con el sentido que históricamente ha tenido el lugar de ubicación de los muertos o cementerio. Desde antes del siglo $\mathrm{X}$, estos lugares se han relacionado directamente con la iglesia católica, ha sido esta institución la principal encargada de administrar las necrópolis y los rituales religiosos ${ }^{5}$.

De acuerdo con Aries (1999), las actuales prácticas sociales y culturales en los cementerios de Occidente, tienen dos momentos claves: el primer periodo, entre la Edad Media y la época moderna, se caracterizó por la realización de las inhumaciones en las iglesias, "verdaderas necrópolis», y un segundo momento en el que, además de las iglesias, se empiezan a construir grandes parques cementerios a los alrededores de las ciudades. En estos dos momentos el autor identifica hechos fundamentales para constituir lo que he dado en llamar los procesos de exclusión o la muerte de la alteridad. El primer momento tiene que ver con el derecho que se arroga la institución eclesial para elegir qué persona es digna de ser sepultada en un cementerio-iglesia y cuál debe ocupar la fosa común, lugar este último, como lo expresa ampliamente el citado autor, "donde se enterraba a los muertos pobres, a aquellos que no pagaban los elevados derechos de inhumación en la iglesia [...]. Se los amontonaba en grandes fosas comunes, auténticos pozos de 30 pies de profundidad de 5 a 6 metros de superficie conteniendo de 1.200 a 1.500 cadáveres» (Aries, 1999, p. 55). En el nivel más bajo de esta jerarquía post mórtem estaban «Los excomulgados, como los supliciados que no han sido reclamados por sus familias, o que el señor justiciero no ha querido restituir, se pudren sin ser enterrados, simplemente cubiertos por bloques de piedra, para no molestar al vecindario (Aries, 1999, p. 44).

El segundo hecho importante tiene que ver con el pago de un derecho a ser enterrado en las iglesias, que surge a mediados de la Edad Media debido a la prohibición por parte de las autoridades conciliares de inhumar cuerpos en los centros religiosos, este hecho generó un proceso de transacción en torno a la muerte que hasta el día de hoy

5 Desde finales de la Edad Media, «Para establecer un cementerio, se construía una iglesia. En un diploma de 870, Luis el Germánico recuerda que sus padres hicieron construir una iglesia, "a fin de que en ese lugar haya un cementerio para los muertos”»(Lesne, E., cfr: Aries, 1999, p. 50) 
se mantiene intacto, una especie de pago por mantener los privilegios de la vida aun después de terminada esta:

«Aparentemente es por un lugar más honorable que el de los cementerios comunes (es decir, por un puesto en la iglesia) por lo que se exigía algo [...] Las sepulturas eran gratuitas en los cementerios, los ricos querían distinguirse haciéndose inhumar en las iglesias» (Thomassin, cfr: Aries; 1999, p. 50).

\section{MUERTE Y COLONIZACIÓN}

"Nosotros traficamos con nuestros muertos la moneda de la melancolía, los Otros viven con los suyos bajo los auspicios del ritual y la fiesta».

\section{BAUDRILLARD}

Como en las prácticas africanas, en los casos de indígenas americanos y afrocolombianos, los rituales funerarios tienen un fuerte sentido de memoria larga (Rivera Cusicanqui, 1986) ${ }^{6}$ y alteridad, en consideración con la importancia que tiene el otro ausente en la definición de la vida presente. Bastantes son los relatos sobre las formas indígenas de enterrar a los muertos; algunos de esos relatos hacen mención de la costumbre de los entierros en las casas, la idea de la convivencia entre el mundo de los vivos y los muertos «un dualismo de una intercomunicación entre las dos dimensiones» (Colón, 2004, p. 38).

En el caso de las poblaciones afrocolombianas y palenques es el baile, la música y la comida la forma de despedir al otro, una «forma de celebrar la vida y simbolizar la muerte» (Colón, 2004), además de generar procesos de memoria colectiva ${ }^{7}$.

6 Esta categoría, se refiere a la pervivencia de la memoria de la lucha anticolonial, en la que se reviven aspectos de las prácticas políticas y comunales de los ayllus — formas organizativas comunales indígenas—, incluidos los relativos a la muerte, como se verá más adelante. Estas luchas se sintetizan en el presente en contra de la exclusión, la discriminación y se expresan como lucha anticolonial.

7 La palabra lumbalú — término de origen bantú que designa las ceremonias funerarias - está compuesta por dos elementos: lu-, un prefijo colectivo, y -mbalú, que significa melancolía, recuerdo. El lumbalú está compuesto no 
En el proceso de colonización de América, los rituales de afros e indígenas fueron excluidos por las prácticas propias de los europeos de inhumar los cuerpos en terrenos considerados "sagrados". Las iglesias del nuevo mundo hechas a «imagen y semejanza de las que ya existían en Europa, eran congregaciones que tenían por objeto acompańar a sus asociados a la hora de la muerte» (Colón, 2004), esta dinámica definió el estilo de ciudades y pueblos del nuevo continente.

Durante el siglo XVIII las prácticas médicas e higienistas empiezan a generar cambios sobre los lugares destinados a los muertos: el temor a las epidemias lleva a sacar los muertos hacía las afueras de las ciudades; la práctica de enterrar en las iglesias, propia de Europa y calcada al pie de la letra en territorio americano, fue prohibida. La disposición de los cementerios a las afueras de las ciudades se convirtió, como sigue siendo hasta hoy, un asunto público privado. En la mayoría de casos, la iglesia católica administra, además de los rituales religiosos, algunos de estos lugares.

\section{NO NOMBRE, NO LUGAR}

A pesar de los avances que Colombia ha alcanzado en materia administrativa en relación con las víctimas en general, en los casos de desaparición forzada se mantienen procedimientos de exclusión que se convierten en nuevas formas de desaparición. La idea de este capítulo es analizar algunos de esos procedimientos de tipo jurídico y práctico que se convierten en mecanismos de revictimización.

Como herramienta metodológica, se utilizan algunos apartes de los diarios de campo que surgieron durante las visitas a los cementerios de Bello, Barrancabermeja, Montería y Pasto como parte del equipo asesor de la Comisión de Búsqueda. Además de algunos análisis desde la antropología de la ley, de algunos recursos jurídicos que se convierten en aliciente de prácticas de exclusión.

sólo por los cantos de muerto sino por todo el ritual de despedida del difunto, en el que participa la comunidad y que tiene por fin «ayudar al difunto a irse de este mundo tranquilo y contento» (Colón, 2004). 
"Aqui hay tres niveles para los entierros: las bóvedas, las gradas y la tierra", "la gente escoge donde quiere y si tiene la plata paga donde quiera". "Se corre la tapa de la fosa común, se meten en una bolsa (los huesos) y se marcan según la tumba donde estaban ubicados, 'estaba en la bóveda 42', si la familia no tiene para comprar el osario entonces se meten aqui o se llevan los restos". "Todo mausoleo tiene su fosa común". (Entrevistas de terreno. Sepultureros de los cementerios de estudio. (Velásquez López, 2009, p. 7).

Colombia cuenta con avances jurídicos en cuanto a la situación de las personas no identificadas en los cementerios del país, el decreto 1333 de 1986, en sus Artículos 268 y 269. Reconoce la responsabilidad del Concejo Municipal en incluir las partidas presupuestales necesarias para la inhumación de cadáveres y la compra de cajas mortuorias y cruces. Este gasto es de obligatorio cumplimiento para los municipios.

En los casos de muertes en el marco del conflicto armado, la ley de víctimas en el parágrafo del artículo 97 dice: En lo no previsto en el presente Decreto para la asistencia funeraria, para las víctimas de desaparición forzada, se estará a lo dispuesto en las normas que reglamenten la Ley 1408 de 2010.

El artículo 7 de la ley de homenaje a las víctimas de la desaparición forzada —Ley 1408 de 2010 — dice: «Los familiares de las víctimas que resulten identificadas, recibirán, por parte del Programa Presidencial para la Acción Social, los recursos necesarios para solventar los gastos funerarios, de desplazamiento, hospedaje y alimentación durante todo el proceso de entrega de cuerpos o restos» ${ }^{8}$.

8 Gran parte de los avances en la búsqueda y recuperación de los cuerpos de las personas desaparecidas se ven reflejados en el cumplimiento del convenio 01 celebrado entre el Ministerio del Interior y de Justicia y la Registraduría Nacional del Estado Civil, en esta labor es fundamental el trabajo realizado por el Instituto Nacional de Medicina Legal en la identificación de personas fallecidas por medio de la comparación de huellas dactilares de los archivos existentes en la Registraduría. Para profundizar en el tema se puede visitar el siguiente link de la página web del Instituto de Medicina Legal. http://www.medicinalegal.gov.co/index.php/ruta-de-atenciona-familiares-de-personas-desaparecidas/322-actualizacion-del-listado-de-personas-identificadas-convenio-01de-2010 
Contrario a lo que plantea la ley, las autoridades reconocen que persisten problemas serios e históricos en torno a la situación de las personas no identificadas en los cementerios. Una nota en el diario de campo de la visita a tres de los cementerios de Montería deja claro cuáles son los principales problemas:

En Montería se visitaron tres cementerios en dos días, pareciera que hubiese recorrido el país entero, los tres lugares recogen gran parte de la problemática de todo el territorio nacional. La tarde del 8 de noviembre estuvimos en el cementerio bosques de Mocarí, del corregimiento con el mismo nombre a las afueras de Montería. Es un cementerio construido por los mismos habitantes, sorpresivamente me entero que en esta región no hay cementerios públicos, según lo que dice el sepulturero, la comunidad va comprando las bóvedas y las va marcando con apellidos y luego las arrienda.

Para el caso de las personas no identificadas, la Alcaldía arrienda bóvedas por un año, cuando pasa este tiempo, los administradores no saben qué hacer. Este cementerio es pequeño y apiñadas por todos lados hay bóvedas. Entre ese laberinto de muertos casi escondidos, están los no identificados con la cifra universal de la exclusión y la pérdida de toda humanidad "NN".

El 9 de noviembre visitamos dos cementerios, el primero tiene la misma característica que el del corregimiento de Mocarí, es un cementerio de la comunidad, en este lugar es evidente que culturalmente pesa más el apellido que el nombre, grandes mausoleos con apellidos en letras grandes en lo alto mirando al cielo, hacen contraste con las casas humildes del barrio que rodea el cementerio.

La administradora del lugar, sabe que está ante una visita oficial del Instituto de Medicina Legal, quizás por esta razón aprovecha el momento para de forma muy rápida contar "todos los problemas que le representan los NN, por culpa del abandono y el desinterés del alcalde”. Según ella, cumple con tener en buen estado los libros organizados por fecha "como debe ser". Pero la Alcaldía sólo ha pagado a los dueños de bóvedas por alquiler de un año para tener a las personas no identificadas, actualmente hay personas no identificadas de tres y cuatro años, los dueños de bóvedas han demandado en varias ocasiones y le han dicho que es su responsabilidad, "que saque 
esos huesos y los bote o sino ellos lo van hacer". Por su parte la Alcaldía le ha respondido en varias ocasiones que esa no es su responsabilidad, que ella verá que hace con esos huesos. Ella por su parte ganó una tutela, pero hasta el momento no ha pasado nada.

El último cementerio fue jardines de la esperanza, un lugar amplio donde contrario a los otros dos, resalta el color blanco de las paredes los verdes de la vegetación y los azules del cielo de tierra calienta, el lugar ante la mirada desprevenida parece limpio, en sus alrededores palmeras grandes que a pesar del calor sofocante dan la sensación de tranquilidad, al fondo una iglesia en forma de quiosco. Durante el recorrido me interpela la flor que ha sido puesta en una de las bóvedas de una persona no identificada, al preguntar me dejan claro que es por el día de los muertos el 1 de noviembre día en que las personas que venden flores les ponen una a cada tumba.

Durante el trayecto me voy pensando, que en medio del olvido literal en el que se encuentran estas personas, siempre hay un instante así sea por tradición en el que se reconoce al otro (algo florece en medio de la nada). Antes de terminar el recorrido entramos a la iglesia a escondernos del sol del final de la tarde que todavía pega con fuerza, la funcionaria del Instituto de Medicina Legal de la región, nos señala que sobre el piso a un costado, debajo de una tapa de metal cerrada con un candado grande y oxidado hay una fosa con cuerpos una "fosa común".

Durante el resto de las visitas a los cementerios este diario de campo se repitió una y otra vez con algunas particularidades. En Pasto, muy formalmente el sacerdote encargado de la administración del lugar nos dio una larga explicación sobre la historia del cementerio, centrándose en las razones injustas de una sanción que les había impuesto la Secretaría de Salud del Municipio, al parecer por no contar con sala de necropsias y tener en mal estado las vías de acceso. De forma particular, el sacerdote resaltó la labor de "caridad" y "beneficencia" por parte de la curia en los 75 años de existencia del cementerio.

En la visita de exhumación en Bello, Antioquia, surgió una nota de prensa y un artículo editorial. 


\title{
Persiste la Búsqueda de Antonio Carvajal
}

\author{
Bello - Antioquia
}

Sobre el mediodía del 11 de marzo de 2003 en el barrio Robledo, nordeste de Medellín, unos hombres armados entraron en la casa de Antonio José Carvajal y se lo llevaron, desde ese día la familia de Antonio sufre un largo peregrinaje por diferentes ciudades del país. 9 años 7 meses, han pasado desde el día en que se lo llevaron. Él, líder social, militante de la Unión Patriótica, esposo y padre... La angustia no cesa y el rostro de Antonio acompaña a los cientos de rostros de la Galería de la Memoria de la Asociación de Familiares de Detenidos Desaparecidos ASFADDES.

El 12 de octubre de 2012, se realiza la jornada de exhumación a una bóveda colectiva con 15 cuerpos, en el cementerio de San Andrés en el municipio de Bello Antioquía, donde se tienen indicios que está el cuerpo óseo de Antonio, en la bolsa número 3 la cual coincide con algunos de los datos entregados por los familiares.

La Comisión de Búsqueda de Personas Desaparecidas CBPD, La Asociación de Familiares de Detenidos Desaparecidos ASFADDES y el Programa de Naciones Unidas para el Desarrollo PNUD, acompañan durante todo el día la jornada de exhumación que realiza el equipo forense de la Fiscalía, con el acompañamiento del CTI y la delegada de la Procuraduría regional.

La primera bolsa en revisar es la número 3, la desesperanza rodea a todo el grupo cuando la fiscal anuncia que este primer resultado es negativo, el cuerpo óseo es el de una mujer, de 22 a 25 años. Para despejar dudas son revisados los demás cuerpos, tomando muestras fotográficas de las placas dentales, dado que a Antonio le faltaban dos muelas y un diente, datos precisos que permitirían una posible identificación.

Al finalizar la tarde el resultado es completamente negativo, de Antonio se sabe con certeza que está en el cementerio San Andrés de Bello - Antioquía. De acuerdo con algunos datos oficiales, en este cementerio el número de personas no identificadas puede pasar de dos mil. El desorden administrativo en los cementerios dificulta mucho más la labor de búsqueda de las personas desaparecidas. 
La Comisión de Búsqueda de Personas Desaparecidas y ASFADDES persisten en encontrar a Antonio, La Fiscalía en los próximos días realizara nuevas exhumaciones en el cementerio de Bello buscando otras personas, el compromiso es tomar muestras de todos los cuerpos esperando que alguno coincida con las señales particulares de Antonio.

\section{EDITORIAL}

El acompañamiento a la diligencia de exhumación en el Cementerio San Andrés de Bello Antioquía, además de la tristeza por no haber logrado hallar el cuerpo óseo de Antonio José Carvajal desaparecido forzadamente el 11 de abril de 2003, dejó serias preocupaciones sobre la forma en la que se encuentran las personas no identificadas en los cementerios del país.

La autoridades en ese momento fueron claras en afirmar que los desórdenes administrativos en los cementerios dificulta la búsqueda de los desaparecidos, la cifra es escalofriante, alrededor de 2000 personas desaparecidas posiblemente se encuentran en este cementerio. La afirmación de las autoridades, se traduce en que son pocos los cuadernos de registros que se tienen de las personas no identificadas que han ingresado al cementerio, que las bolsas con los cuerpos óseos muchas de ellas no están marcadas, que las bóvedas colectivas llegan a números exorbitantes, (como en el caso de la bóveda que se exhumo para buscar a Antonio, tenía 15 cuerpos óseos uno tras de otro), que en muchos casos los cuerpos son trasladados de bóveda sin registro alguno, en fin, todo concluye en que en este caso la búsqueda va ser mucho más larga de lo esperado, es contradictorio pero al desaparecido no sólo lo desaparecen sus verdugos.

Esta situación se une a las denuncias realizadas en el año 2012 en Barranquilla por la Asociación de Familiares Unidos por un solo Dolor (AFUSODO), en ese momento los familiares denunciaron la grave situación de los cuerpos óseos que han sido arrojados a fosas comunes en los cementerios de Valledupar, Montecristo Bolívar, Ciénaga, Maicao, Tierra Alta, Dibulla y San Juan del César. 
Desde el año 2010 la Comisión de Búsqueda viene haciendo especial énfasis en la falta de cumplimiento de la resolución 1447 de 2009, emanada del Ministerio de la Protección Social "por la cual se reglamenta la prestación de los servicios de cementerios, inhumación, exhumación y cremación de cadáveres".

La situación de los cementerios es grave, para lograr establecer la dimensión de la problemática es necesario visitar uno a uno los cementerios de las ciudades, como lo vienen haciendo los delegados y comisionados.

\section{LA EXCLUSIÓN DE LA LEY}

Como ha quedado ampliamente explicado en los diarios de campo y notas de prensa anexas a este capítulo, las situaciones administrativas que se presentan como simples errores de procedimiento, se configuran realmente en una doble desaparición, una forma de prolongar el dolor de la ausencia?

Son múltiples las razones para que este tipo de situaciones se repitan cotidianamente en gran parte del territorio nacional, pero de acuerdo a esta investigación el hecho evidente es que ha existido históricamente una serie de mecanismos y formas de legitimación de la desaparición forzada por parte de estructuras del Estado, no sólo en la ejecución del hecho mismo, sino en la justificación, en la impunidad que existen en la mayoría de los casos, en la invisibilización de la problemática y ante todo, en los procesos jurídicos y legislativos que han terminado de rezagar y minimizar la situación.

9 Sobre este tema de la ausencia y recuperación del cuerpo óseo, es importante tener en cuenta los aportes de las organizaciones de familiares de víctimas de desaparición forzada, especialmente la Asociación de Familiares de Detenido Desaparecidos - ASFADDES —, que contrario a los estudios psicosociales que estudian los procesos de exhumación y recuperación de los cuerpos óseos como parte de la "reparación” y la realización de un posible "duelo", ASFADDES profundiza desde la práctica, en la complejidad y contradicción de los procesos de exhumación, dado que, si bien es importante recuperar el cuerpo, no es tan simple la ecuación que confirman la teoría del duelo, por el contrario la recuperación del cuerpo supone a la vez la perdida de la esperanza que en muchos casos es el motor de procesos de resistencia de largos ańos. 
Para el siguiente análisis se tendrán como referencias, el concepto de Antropología de la ley, teniendo en cuenta la definición que realiza el profesor Castillejo: en este sentido la "Ley no se ve como un ámbito (de especialistas) ajeno a la sociedad, sino como parte de campos más amplios de relaciones de poder. Desde esta perspectiva, la ley es un artefacto cultural." (Castillejo, 2011, p. 14). Además, de la experiencia recopilada a lo largo de más de cinco años de relaciones de mutua confianza con la Asociación de Familiares de Detenidos Desaparecidos (ASFADDES), ${ }^{10}$ para este caso la mayoría de referencias a los contextos históricos sobre la evolución jurídica del crimen, hacen parte de la historia que durante más de 30 años han escrito con dolor los familiares de las personas desaparecidas en el país.

“...La desaparición Forzada en Colombia, comienza a aplicarse en el marco de la doctrina de la seguridad Nacional, a finales de la década de los setenta, incrementándose en la década de los ochenta, como modalidad represiva y sistemática para eliminar opositores políticos y como mecanismo de represión, cuando se institucionaliza la violación de Derechos Humanos en Colombia (...) En estas dos décadas este crimen atroz se caracterizó por ser selectivo, previa vigilancia, seguimientos, operativos de inteligencia y ejecución por parte de organismos de seguridad del Estado sobre las víctimas”. (Gómez, 2008, p. 107).

En estos primeros años, la no tipificación del delito y la participación directa de agentes del Estado fue un factor determinante en el rechazo y la exclusión que afrontaban los familiares de las personas desaparecidas. Este tipo de prácticas fueron evidentes en acciones cotidianas, muchos de los relatos de estos años explican a profundidad, la forma en que los familiares eran excluidos "En la marcha de todos los jueves alrededor de la plaza de Bolivar; nos cerraban la catedral, nos gritaban viejas locas, viejas sin oficio, la Policía nos quitaba los carteles y nos echaba gases, incluso hasta los compañeros de los sindicatos y las organizaciones sociales nos decian las lloronas". ${ }^{11}$

10 ASFADDES surge en 1982 tras la desaparición forzada de trece personas en su mayoría estudiantes de las universidades Nacional y Distrital. Para profundizar en la historia de ASFADDES se puede ingresar a www.asfaddes.org.

11 Se debe tener en cuenta que el proceso de resistencia de los familiares de las víctimas en Colombia ha sido liderado por las mujeres y en ese sentido, ellas han sufrido los rechazos propios de una sociedad patriarcal 
De esta manera se ha ido configurando lo que yo llamo la doble desaparición, la desaparición forzada que hace referencia a la acción violenta y una desaparición social y cultural que tiene que ver con las prácticas de cotidianas de exclusión en las que instituciones públicas ${ }^{12}$, medios de comunicación, instituciones religiosas y entidades privadas son sus principales emisarios. En ese sentido la falta de legislación y reconocimiento de la desaparición forzada es un factor de cultural que avala y legitima la exclusión.

\begin{abstract}
"A finales de la década de los ochenta y principios de los noventa, la desaparición forzada pasó a ser no sólo selectiva, sino que se convirtió en una práctica masiva de terror, extendiéndose a todos los sectores sociales, líderes populares, urbanos y rurales, aplicándose también a personas que por el solo hecho de habitar o transitar en zonas de grandes riquezas naturales, fuertes procesos sociales y agudo conflicto armado, se convirtieron en víctimas, engrosando las listas de desaparecidos existentes (...) Caracterizándose en su ejecución por ser grupos de paramilitares, que actuaban en complicidad, tolerancia y aquiescencia del Estado" (Gómez, 2008, p. 2).
\end{abstract}

Cada uno de los avances en materia jurídica en torno al delito de la desaparición forzada, han sido logros de la presión y denuncia de los familiares de los desaparecidos. En la constitución de $1991^{13}$, las organizaciones de familiares avanzaron en el reconocimiento de la práctica en el marco de la nueva legislación.

y machista. Este aparte de testimonio es lo que se define como memoria colectiva, porque no hace parte de un testimonio individual sino de una historia que es repetida una y otra vez por las personas que vivieron ese momento, pero también por otras generaciones que se han apropiado de esa historia.

12 En términos jurídicos, hasta hace poco tiempo no existían leyes que permitieran la reclamación de bienes por parte de los familiares a menos de que se realizará la declaración de muerte presunta. Después del año 2000 con la tipificación del delito a través de la ley 589, y debido a la labor de la Comisión de Búsqueda y la presión de los familiares de las víctimas surge la "Administración de bienes". En el periodo correspondiente se explica en detalle este procedimiento jurídico.

13 Si bien es cierto que la figura de dictaduras de finales de la década de los 60, los 70 y principios de los 80 en Colombia no se dio, sí es muy interesante ver como se han venido constituyendo lo que los teóricos llaman procesos de "transición" en cuanto a entrega de armas, procesos de paz y amnistía. En ese sentido es interesante analizar la relación directa que tienen estos procesos con la formulación y aplicación de políticas relacionadas al fortalecimiento de la economía neoliberal. Por ejemplo: a finales de los 80 se adelantaron procesos de paz con las diferentes guerrillas, se desmovilizaron las guerrillas del M19, el PRT, El Quintin Lame y el EPL y se construyó 
El cambio en el modus operandi de la desaparición forzada, facilitó el reconocimiento del hecho por parte del Establecimiento, puesto que la acción directa en estos casos ya no recaía en agentes del Estado, sino en grupos de paramilitares que a pesar de tener el apoyo de sectores estatales fueron reconocidos como "grupos al margen de la ley". ${ }^{14}$ Durante este periodo de tiempo, en el papel la acción de desaparecer fue rechazada y prohibida, aunque en materia de administración de Justicia el delito de la desaparición forzada tomó 9 años más en ser tipificado, lo que significó que durante la década de los 90 los familiares tuvieron que denunciar el hecho como secuestro simple, homicidio y otro tipo de delitos que desfiguran las razones políticas del crimen. En resumen, los desaparecidos existen en cuanta negación de los perpetradores.

La existencia de la figura del desaparecido es un artículo escrito en la constitución, porque para acciones de tipo administrativo y legal, — por ejemplo la reclamación de un predio o la asignación de pensiones y cesantías por parte de los familiares de las personas desaparecidas_- fue necesario que al desaparecido se le declarara muerto. La figura existencial que han construido los familiares de las víctimas, desde la idea de la reconstrucción de la memoria de los sueños y luchas de los desaparecidos, como parte de un proceso de resistencia contra el olvido, en este periodo de tiempo fue irrelevante para los administradores de justicia, quienes durante más de una década sólo entendieron el lenguaje del pragmatismo y la dicotomía entre los vivos y muertos, _-aunque en el caso de las desapariciones no se comprueba la muerte física, sino que se hacen todo tipo de suposiciones_- El familiar de la víctima en los años 90, fue obligado a dar por muerto a quien todavía esperaba.

una nueva carta legislativa basada en la idea de un Estado Social de Derecho, en esa misma línea se consolidó el proceso de apertura económica, privatización y desregulación de actividades económicas y de prestación de servicios públicos. Algunos analistas ven esta situación como una profunda contradicción política, no obstante puede considerarse este proceso como la disposición de una serie de medidas políticas y sociales que permiten y amortiguan los efectos de decisiones económicas. Un ejemplo actual es la legislación jurídica en el marco de la justicia transicional (ley 975, ley de víctimas y restitución de tierras, marco jurídico de paz) y la firma del TLC entre Colombia y Estados Unidos. (Muńoz, 2013, p. 380).

14 El cómo se califica, se menciona y se nombran los hechos, construye nuevas realidades y formas culturales de recordar el pasado. 
"El nuevo milenio trajo consigo la maquinaria de muerte y el desborde de la crisis humanitaria, con máxima expresión de crueldad específicamente en la desaparición forzada, siendo utilizada como práctica indiscriminada de dominio y exterminio de comunidades y poblaciones en regiones de intereses económicos y territoriales. Llenando de miedo, pánico y terror a los familiares de las víctimas, que para conservar sus vidas han tenido que convertir el silencio y la mordaza, contradictoriamente en garantía de vida, situación que ha impedido dimensionar la realidad de la tragedia de la desaparición forzada en Colombia” (2008, pp. 2-3).

En la actualidad, los mecanismos de exclusión son mucho más elaborados y administrados. La dimensión de la tragedia de la desaparición forzada en el país, desborda la capacidad estadística de violentólogos y en este último periodo de tiempo, de memoriólogos, que se han empeńado en contar retazos de historias a través de casos emblemáticos.

Las leyes con relación a las víctimas y el conflicto decretadas en la última década, se enmarcan en la reconocida teoría global de la justicia transicional, basada principalmente en el reconocimiento de los derechos a la verdad, la justicia y la reparación. ${ }^{15} \mathrm{La}$ teoría de la justicia transicional se construye sobre la base de los derechos históricos de sobrevivientes y víctimas, el asunto se complejiza a la hora de analizar en detalle las formas y procedimientos que hacen posibles el acceso a la verdad, la justicia, la reparación y la memoria. Son estos dispositivos en su mayoría de tipo jurídico y político los que cumplen la función de recolonizar y recodificar (Aranguren, 2012, p. 114) lo que en un pasado se erigió como sendas apuestas políticas y contrahegemónicas de las organizaciones sociales.

Someter los saberes (Aranguren, 2012, p. 114) de las organizaciones por parte del Estado y enmarcar estas apuestas en políticas públicas, se convierte en una nueva forma de exclusión desde el lenguaje de la inclusión y el acceso a los derechos. En este

15 "Una serie de cuestionamientos han planteado la necesidad de ver la implementación de estas leyes desde un registro cotidiano...En la medida en que constituyen no sólo un contexto de aplicación jurídica sino también, y en particular, un escenario de negociaciones simbólicas donde concepciones más abstractas del pasado y del futuro se entrelazan de maneras complejas con nociones más inmediatas como la de la "víctima” y la de la "reparación” (Castillejo, 2011, p. 30). 
caso es importante preguntar lo elemental, ¿cuál es la concepción de verdad y justicia que se construye en el marco de leyes como la 975 y la 1448 ?

En el caso concreto de las desapariciones forzadas, la exclusión de la ley es evidente, en todo el articulado de la ley de víctimas sólo existe una mención al tema cuando dice: una de las medidas de satisfacción "será la de "contribuir" en la búsqueda de los desaparecidos y "colaborar" para la identificación de cadáveres y su inhumación posterior según las tradiciones familiares y comunitarias a través de las entidades competentes para tal fin". Si se tiene en cuenta la dimensión de la problemática de la desaparición forzada en el país y la forma como es concebida y redactada la ley, es contradictorio que la máxima legislación en materia de víctimas en el país, reconozca la acción del Estado para con las víctimas de la desaparición, con verbos débiles que hacen referencia a procesos de solidaridad y beneficencia.

La ley de víctimas ha logrado consensos en amplios sectores de la sociedad, alrededor de esta legislación existe un aparataje de relaciones económicas nacionales e internacionales en las que se mueven organismos de derechos humanos, ONGs nacionales e internacionales y todo un sector humanitario que hace parte de la implementación de esta legislación. A pesar de algunas críticas, esta legislación se reconoce como el avance más significativo que existe actualmente en el país en materia de víctimas, en esa idea resulta relevante preguntar ¿Dónde están los desaparecidos en todo este aparataje? ¿Qué significado y sentido tienen las víctimas de la desaparición forzada para el enorme aparataje interinstitucional que hace parte de la ley de víctimas? ¿Acaso la visibilización y reconocimiento de unos tipos de delitos por parte de grupos ilegales y agentes del Estado, supone la exclusión de otros crímenes de orden estructural?

A pesar del desconocimiento por parte de la ley de víctimas, es importante reconocer la labor de la Comisión de Búsqueda de Personas Desaparecidas, organismo permanente creado mediante La Ley 589 de 2000 que tipifica el delito de desaparición forzada. Esta entidad es conformada por nueve instituciones y organizaciones interestatales. 
En 12 años de labores, la Comisión ha logrado reconocidos avances jurídicos en materia de desaparición forzada. ${ }^{16}$

Lo contradictorio del caso es que muchos de los avances de la entidad son relegados por asuntos de mayor importancia en la agenda política, a modo de ejemplo; es interesante analizar como la ley de homenaje a las víctimas de la desaparición forzada - Ley 1408 de 2010 - recoge en gran parte la concepción de memoria desde las organizaciones de familiares y aunque está en vigencia desde hace dos años, ha sido completamente excluida del espectro político, hasta el punto que entidades territoriales desconocen por completo sus articulados. Haciendo una metáfora se podría afirmar que la ley de victimas - 1448 - cooptó todos los espacios políticos, sociales y culturales haciendo imposible el reconocimiento de otras leyes relacionadas con el tema de las víctimas.

En el último capítulo profundizo en la construcción de mensajes en torno al tema de desaparición forzada y la construcción de la muerte, sólo para anotar que la ley de víctimas actualmente cuenta con grandes presupuestos en materia de comunicaciones y construcción de mensajes, hasta el punto de excluir y anular cualquier otro tipo de legislación del campo mediático y de opinión.

Durante la redacción de este capítulo se desarrolla una noticia que ejemplifica perfectamente lo que en las páginas anteriores llamé como la exclusión de la ley, el Estado Colombiano presentó ante la Corte Interamericana de Derechos Humanos una defensa sobre el caso de las 12 personas desaparecidas en el Palacio de Justicia, basado en el argumento de negación de los hechos. Lo que al parecer es contradictorio

16 Avances materializados principalmente en: el Plan Nacional de Búsqueda, el Mecanismo de Búsqueda Urgente, el Registro Nacional de Desaparecidos, el impulso y gestión de la ley 1408 de 2010 por la cual se rinde homenaje a las víctimas de la desaparición forzada, la ley 1418 de 2010 por medio de la cual se aprueba la "Convención Internacional para la Protección de todas las Personas contra las Desapariciones Forzadas”, adoptada en Nueva York el 20 de diciembre de 2006. La Administración de Bienes; mecanismo de protección de los bienes de las personas víctimas de la desaparición forzada, introducido por la Ley 589 de 2000, que autoriza a los familiares del desaparecido a asumir de manera provisional la disposición y administración de todos o parte de los bienes de la víctima. Diferente a lo que sucedía en el pasado con la declaración de muerte presunta. Cada uno de estos documentos se encuentran en el sitio web de la Comisión de Búsqueda de Personas Desaparecidas —CBPD— www.comisiondebusqueda.com 
y polémico es que tal defensa además de desconocer los derechos de las víctimas, desconoce el informe de la comisión de la verdad creada en el caso del Palacio de Justicia, en el que se confirman los hechos. Lo que pareciera una contradicción a la política oficial de reconocimiento de las víctimas, se configura más bien como una forma de demostrar la debilidad de los mecanismos oficiales no judiciales de justicia, como las comisiones de la verdad y los informes de memoria. (Sanchez, 2013).

\section{ENARBOLANDO DIGNIDAD}

En el 2008 durante la realización de entrevistas para el documental de ASFADDES en la conmemoración de los 25 años de la organización, tuve la posibilidad de entrevistar a Javier Darío Restrepo, reconocido periodista colombiano quien ha desarrollado a profundidad el tema de la ética periodística. La idea de la entrevista era comprender por qué los medios históricamente han sido indiferentes a la problemática de la desaparición forzada, generando alrededor del crimen siempre un manto de silencio y duda.

De forma muy sencilla él respondió algo así como: la construcción de la noticia se basa en la idea elemental del espectáculo, para eso se necesitan una serie de características que hacen que un hecho se convierta en tal, por ejemplo; un robo a mano armada en una calle es una noticia porque al momento de llegar el reportero puede entrevistar a las personas que dirán más o menos que sucedió, por donde cogió el ladrón, cuáles son sus características físicas. La víctima del hecho amplía lo sucedido si se encuentra en buen estado de salud, de lo contrario se hace un plano general a la clínica u hospital en el que se encuentra internado. Si fue asesinado, saldrá una foto del cuerpo en la calle con una sábana en el rostro. Sobre este esquema predeterminado, se montan las noticias, sean estas de robos, de muerte, de secuestros o de tomas guerrilleras.

La desaparición forzada no hace parte de ese esquema de noticias, la persona que fue testigo del hecho no está dispuesto a hablar o por lo menos no en los medios de comunicación, no hay un cuerpo al cuál fotografiar, no hay vecinos para entrevistar, lo único que hay es silencio y miedo. Un reportero en esas condiciones 
no está dispuesto a cubrir nada, se necesitaría — afirma tajantemente el periodista Javier Dario Restrepo-, periodistas dispuestos por un lado a trasgredir ese orden preestablecido para hacer noticias y por otro seres humanos que ejerzan la labor de comunicar con profunda "sensibilidad humana" para preguntar por lo elemental y existencial. Ańade, además, que el marco de la noticia de 30 segundos no es el formato que permite este tipo de cubrimientos.

\section{LA MUERTE EN LOS MEDIOS}

"Comprender es casi justificar"

\section{Primo Levi}

Los medios de comunicación son un elemento más de la construcción de la muerte en occidente, una muerte basada en el mito platónico del tránsito a un mejor lugar y mediada por las relaciones de tipo económico, social y político. En ese sentido, en una sociedad capitalista e industrial se construyen también industrias de la muerte y verdaderas necrópolis.

Sabemos lo que significan esos lugares inencontrables: si la fábrica ya no existe es porque el trabajo está en todas partes [...], si el cementerio ya no existe es porque las ciudades modernas asumen por entero su función: son ciudades muertas y ciudades de muerte. Y si la gran metrópoli operacional es la forma lograda de toda una cultura, entonces, simplemente, la nuestra es una cultura de muerte. (Baudrillard en Herranz, 2008, p. 92).

Las industrias de la muerte construyen necesariamente formas de relato que se pueden consumir "desde un sofá", estadísticas e historias de vida que permitan contar en tercera persona lo efímero que resulta el drama y la tragedia ${ }^{17}$ una muerte, como diría Baudrillard, hiperreal: un mero espectáculo que se consume desde el sillón de casa.

17 Sobre este tema se puede ver el trabajo "La construcción mediática de la muerte. Un estudio desde la filosofía, la antropología y la semiótica”, de Juan Carlos Herranz y Mónica Lafon en Estudios 87, vol. VI, invierno 2008. 
La experiencia de la muerte es a la vez la experiencia de la alteridad, es el sentido del otro ausente. Occidente a diferencia de otras culturas ha construido esta idea sobre la base de la ruptura entre dos entidades: la carrera de aquel ser maravilloso, llamado hombre, y su fatal destino. (Herranz, 2008, p. 92).

La desaparición forzada en cambio es un dispositivo de control social, aplicado por sistemas políticos que reconocen el valor y la importancia de la explotación y la "administración" del miedo y la negación de la muerte como mecanismos para quebrantar formas de resistencia social. En la desaparición forzada, no existe tal sentido de alteridad, la vida se detiene en un espacio de tiempo contradictorio para familiares y amigos de la persona desaparecida.

Los primeros días, la búsqueda incesante entre personas conocidas, luego entre hospitales, morgues y botaderos de cadáveres. - Se tiene la certeza que no hay muerte sin cuerpo- - A los años, la vida se establece en medio de la contradicción, de sentir en ocasiones que el desaparecido ha muerto después de tanto tiempo sin tener ninguna noticia. Luego un olor, un rostro en la calle o la silueta de alguien al caminar, afloran la esperanza, esa misma, que no permite cambiar de lugar sus pertenencias, esa que hace que se mantenga siempre el cuarto detenido en el tiempo o esperando todas las noches que el desaparecido ocupe su puesto en el comedor para cenar. A la mañana siguiente, de nuevo la idea de que debe estar muerto y entre esos sentimientos constantes se va la vida, los rostros cuarteados por las arrugas, hacen contraste con la imagen ya universalizada del rostro en blanco y negro de la fotografía de un retablo. "Por siempre joven nos mira la foto de ayer y hoy" canta León Gieco.

El testimonio para los medios sólo es posible si no profundiza asuntos complejos, por eso es clave el llanto en primer plano que resuma de forma efímera todo lo existencial y ontológico, y la "víctima" pasiva, que solamente reclame los huesos de su ser querido sin pedir más que una reparación en muchos casos económica. Los medios han construido formas de exclusión relacionadas profundamente con las agendas oficiales en torno al tema. De esta forma, se debe entender el punto de giro que tuvo la problemática durante el año 2005 cuando fue tipificada la ley de justicia y paz, de forma para nada sorpresiva los medios se volcaron a contar en cifras cuantos 
huesos estaban siendo exhumados, la Fiscalía General de la Nación se convirtió en una fuente constante de este proceso.

En ese momento, el formato dio un giro y los testimonios de las víctimas resultaron ser importantes para el contexto social, político y económico del país. El modelo global de la reconciliación ${ }^{18}$, además de profesar el reconocimiento de los derechos de las "víctimas" a la verdad, la justicia y la reparación, está compuesto de mecanismos para administrar los testimonios, ${ }^{19}$ de ahí que exista una suerte de consenso entre los medios de comunicación, las instituciones del Estado y algunas organizaciones sociales y de víctimas, frente a las formas de abordar los testimonios y la capacidad que estos tienen de "cerrar heridas", "liberar" o "sanar". Una forma clara de ejemplificar lo anterior es un mensaje de una "víctima del conflicto" puesto vía twitter por la Unidad de Victimas el día 05 de marzo de 2013: "sentirnos escuchadas es lo más importante”.

En ese contexto es necesario volver a las preguntas elementales ¿Cuál es el valor real del testimonio?, ¿A quiénes interpela?, ¿A quiénes convoca? Parafraseando a Joan Carle Melich ¿Cómo construir una ética de la memoria que acoja al otro sin condiciones, que acoja a ese muerto anónimo, a ese número que asesinan? ¿Acaso se trata de ubicar retazos de historias del dolor de víctimas, en un periodo de tiempo ubicado en el pasado? en la magnificación de la palabra acerca del pasado ¿Dónde se ubican las apuestas de futuros? ¿Cuáles son los silencios estructurales que se quedan en medio de toda la polifonía de voces de víctimas? ${ }^{20}$

18 Agradezco al profesor Alejandro Castillejo los espacios cotidianos para hablar largas horas de estos temas, su reconocida labor intelectual se convierte en un aliciente para buscar e indagar por los límites de la palabra en situaciones de guerra.

19 Para profundizar en este tema ver Aranguren Romero, J. P. (2012). La gestión del testimonio y la administración de las víctimas: el escenario transicional en Colombia durante la Ley de Justicia y Paz. Bogotá: Siglo del hombre editores y CLACSO.

20 "El testimonio por definición tiene lo que podrían llamarse silencios que son "instalados", difíciles de hablar por razones culturales o de otra índole y que las sociedades "no se dan cuenta que no se dan cuenta” (Castillejo, 2013, p. 10). 


\section{Notas AL PIE}

Para finalizar este ensayo algunas notas a modo de provocación, en el sentido de llamar la atención sobre la importancia de investigaciones de largo alcance que analicen los múltiples matices de un crimen que no ha parado de cometerse a través del tiempo en el país. Es importante detener la mirada un momento y preguntar ¿Por qué en los casos de desapariciones forzadas a nivel global impera la impunidad? $Y$ en esa medida reconocer que el horizonte de justicia planteado por el movimiento de familiares de las víctimas a nivel mundial, no pasa necesariamente por las leyes de reconciliación o de Justicia Transicional.

Desconocer los avances de las instituciones, es en parte desconocer el proceso histórico de los familiares de las víctimas que han hecho posible que se tomen medidas entorno a la problemática. Pero el tema de los cementerios, pone de plano la necesidad del reconocimiento por parte del Estado de las causas estructurales que permitieron que prácticas de exclusión de orden social, político, jurídico y cultural, se configuraran e hicieran carrera hasta el punto de que en el presente no es posible calcular cuántas son las personas desaparecidas y cuáles están en los cementerios, en las fosas comunes, en los basureros, en las cunetas, en el fondo de los ríos y lagos.

Ahora, que al parecer se le está prestando atención a lo que tienen por decirnos los que han sufrido el horror, es necesario entender que el asunto es más complejo que la idea de construir cementerios como lugar para lleguen los desaparecidos y sean tratados con respeto. Se trata de subvertir ideas culturales en torno a la muerte que han sido arraigadas hasta el punto de la naturalización de la exclusión. Se podría decir, que todos los aspectos de la exclusión se configuran en el único hecho de no contar con un lugar para la muerte. 


\section{REFERENCIAS}

Aranguren Romero, J. (2012). La gestión del testimonio y la administración de las víctimas: el escenario transicional en Colombia durante la Ley de Justicia y Paz. Bogotá: Siglo del hombre editores y CLACSO.

Aries, P. (1999). El hombre ante la muerte. Madrid: Taurus 1999.

Asociación de Familiares de Detenidos-Desaparecidos (Asfaddes) (2003). Veinte años de historia y lucha. Asfaddes con todo el derecho. Bogotá: Rodríguez Quito.

Castillejo A. (2011). Guerra Cotidianidad y los órdenes globales Notas antropológicas para una relectura de la violencia en Colombia. En Jairo Tocancipa (ed.) "Antropologías en Colombia: Trayectorias, tendencias y desafíos contemporáneos”, Popayán: Universidad del Cauca.

Castillejo A. (2011). Tras los Rastros del Cuerpo: Instantáneas Del Proceso de Justicia y Paz en Colombia. Bogotá: Universidad de los Andes.

Castillejo, A. (2013). Voces [en la cabeza]: espacialidad, mediaciones teletecnológicas y las verdades caleidoscópicas en el proceso de Justicia y Paz en Colombia. Papeles del CEIC \# 92, marzo 2013. Recuperado noviembre de 2014. http://www.identidadcolectiva.es/ $\mathrm{pdf} / 92 . \mathrm{pdf}$

Centro de Memoria Histórica (2012). Justicia y paz: ¿verdad judicial o verdad histórica? Bogotá: Taurus, Publicaciones Semana y Centro de Memoria Histórica.

Colón L. C. (2004). "Espacios para los muertos y ritos para la memoria”. En: Las ciudades y los muertos. Cementerios de América Latina. Bogotá: Alcaldía Mayor de Bogotá e Instituto Distrital de Cultura y Turismo.

Gómez, G. (2008). Asfaddes: historia de amor, lucha y resistencia. Recuperado de www.asfaddes.org. 
Herranz, L. (2008). "La construcción mediática de la muerte. Un estudio desde la filosofía, la antropología y la semiótica”, Estudios (87), vol. VI, invierno 2008.

Lanceros, P. (2000). "Escribir en el agua”. En: Revista Sileno: Variaciones sobre arte y pensamiento, N. ${ }^{\circ}$ 9. Madrid: Abada Editores.

Ley de víctimas y restitución de tierras (2011). Recuperado de: http://www.derechoshumanos.gov.co/Documents/130220-1-cartilla-ley-victimas-restitucion-tierras.pdf

Lopes, G. (2011). El fin de la democracia: un diálogo entre Tocqueville y Marx. Bogotá.

Mèlich, J. C. (2001). La ausencia del testimonio. Ética y pedagogía de los relatos del holocausto. Barcelona y Guadalupe: Anthropos y Universidad Autónoma Nuevo León.

Muñoz, C. A. (2013). "Acercamiento al concepto de memoria desde la visión crítica de la democracia”. En: Violencia, memoria y sociedad: debates y agendas en la Colombia actual. Castillejo, A. y Reyes, F. L. (eds.). Bogotá: Ediciones USTA. pp. 375-387.

Rivera Cusicanqui, S. (1986). Oprimidos pero no vencidos. Luchas del campesinado aymara y quechwa, 1900-1980. La Paz: Hisbol.

Ruta de Atención a los familiares de personas desaparecidas. Recuperado de: http://www.medicinalegal.gov.co/index.php/ruta-de-atencion-a-familiares-de-personas-desaparecidas/322actualizacion-del-listado-de-personas-identificadas-convenio-01-de-2010.

Sanchez, N. (2013). Palacio de Justicia: ¿la mejor defensa es el ataque? Recuperado de: http:// www.semana.com/opinion/articulo/palacio-justicia-la-mejor-defensa-ataque/333967-3

Thomas, L. V. (1983). Antropología de la muerte. México: Fondo de Cultura Económica.

Velásquez P. (2009). Los cementerios...territorios intersticiales. Hacia la Promoción de la Salud, Volumen 14, No.2, julio - diciembre 2009, pp. 24-38. 